Cita bibliográfica: Belino Bonfim, I.O., Dalila Corbari, S, Da Costa Mendes, J.y Dias Serqueira, B. (2022). Representaciones sociales sobre el desarrollo del turismo en tierras indígenas Terena. Investigaciones Turísticas (23), pp. 314-338. https://doi.org/10.14198/INTURI2022.23.14

\title{
Representaciones sociales sobre el desarrollo del turismo en Tierras Indígenas Terena
}

\section{Social representations regarding the development of tourism in Terena Indigenous Land}

Izac de Oliveira Belino Bonfim (iD) Universidade Federal de Mato Grosso do Sul, Brasil izac.bonfim@ufms.br

Sandra Dalila Corbari iD Universidade Federal do Paraná, Brasil corbari91@hotmail.com

Julio da Costa Mendes (iD, Universidade do Algarve, Portugal

jmendes@ualg.pt

Bernadete Dias Serqueira (iD, Universidade do Algarve, Portugal

bsequei@ualg.pt

\section{RESUMEN}

Las Tierras Indígenas (TI) son porciones territoriales que, luego de pasar por un proceso administrativo de demarcación, garantizan la posesión y usufructo de las tierras, por parte de una o más comunidades indígenas. En estos territorios se pueden desarrollar distintas actividades económicas, incluido el turismo. Este estudio tiene como objetivo comprender las representaciones sociales (RS) en el desarrollo del turismo en las TI Terena y la sociedad de Aquidauana (Brasil), involucrada directa e indirectamente con la incipiente actividad turística en las TI del pueblo Terena y su potencial desarrollo. Para la realización de la investigación se eligieron diferentes procedimientos metodológicos. En la investigación se utilizaron fuentes bibliográficas primarias y secundarias y se estableció contacto con los Terena a través de la observación directa no estructurada en las TI Limão Verde y Taunay/Ipegue, incluyendo también áreas retomadas. Además, se realizaron entrevistas dialogadas con actores sociales no indígenas del área urbana y rural de Aquidauana. Para el tratamiento de las RS se utilizó la metodología de análisis del Discurso Colectivo del Sujeto (CSD). Se concluye que los entrevistados han encubierto el racismo y otros prejuicios. Como consecuencia, existe incredulidad en la capacidad de las comunidades Terena para gestionar el turismo en sus tierras.

Palabras claves: Representación social; Terena; turismo en tierras indígenas 


\begin{abstract}
Indigenous Lands ( $\mathrm{TI})$ are territorial portions which, after undergoing an administrative process of demarcation, guarantee the possession and enjoyment by one or more indigenous communities. Certain economic activities are developed on these lands, including tourism. This study seeks to gain an understanding of the social representations (RS) in the development of tourism in the Terena Nation lands and the society of Aquidauana (Brazil) involved directly and indirectly in the tourist activity on the Terena Indigenous Lands and its potential development. To carry out the research, different methodological procedures were chosen. Primary and secondary bibliographic sources were used and contact was established with the Terena Nation through direct unstructured observation, in the TI Limão Verde and Taunay/Ipegue, also including reclaimed areas. In addition, dialogue-based interviews were conducted with non-indigenous social actors from the urban and rural areas of Aquidauana. For the treatment of SR, the Discourse of the Collective Subject (DCS) analysis methodology was used. It is concluded that the interviewees veiled racism and other prejudices. As a consequence, there is skepticism as to the ability of the Terena people to manage tourism on their land.
\end{abstract}

Keywords: Social representation; Terena nation; tourism on indigenous lands

\title{
I. INTRODUCCIÓN
}

El estado de Mato Grosso do Sul está ubicado en la región del Medio Oeste de Brasil, en la frontera con Paraguay y Bolivia. Su principal base económica es la agroindustria, especialmente la producción de productos básicos como cereales y ganado de carne (Mato Grosso do Sul, n. d.). Sin embargo, el turismo también es una actividad económica importante, con énfasis en el ecoturismo, que incluye la observación de flora y fauna, paseos de observación del paisaje, safaris fotográficos, pesca amateur y deportiva, paseos en bote, entre otras actividades recreativas, que se basan en la interacción y observación de naturaleza. Los principales destinos turísticos nacionales e internacionales son las áreas cubiertas por el bioma Pantanal y la región Bonito/Serra da Bodoquena (Observatório de Turismo do Mato Grosso do Sul [Obstur], 2020).

Es importante resaltar que la población indígena de Mato Grosso do Sul, en 2010 sumaba más de 130,494 personas (3\% de la población total del estado) según el Instituto Brasileño de Geografía y Estadística (IBGE) (2010), dividida entre las etnias Terena, Ofaié, Guató, Kinikinau, Atikum, Kadiwéu, Guarani Ñandeva y Guarani Kaiowá (Subsecretaria Especial de Cidadania [SEDIC], 2019). En Aquidauana, municipio ubicado en la llanura prePantanal, la población indígena representaba el 12\% de la población en 2010 (IBGE, 2010), habitando en cuatro Tierras Indígenas (TI) (Instituto Socioambiental [ISA], 2020). Además, hay algunas áreas 'retomadas', porciones del territorio tradicional Terena que están en posesión actual por los terratenientes. Esas áreas ocupadas ilegalmente son demandadas por los Terena.

La diversidad sociocultural indígena brasileña, sumada a los atractivos naturales presentes en las $\mathrm{TI}$, hacen que estos territorios tengan interés para potenciales visitantes. En 
América Latina, existen varios casos en los que territorios indígenas están orientados a las visitas de extranjeros, los mismos no están orientados a la población nacional, la cual sigue considerando a los indígenas como personas pobres, inferiores, sin posibilidades para su superación y desarrollo (Pereiro, 2013). Desde la comprensión de esta realidad en el territorio brasileño y desde la experiencia en Aquidauana/MS - donde el espacio es escenario de varios conflictos entre indígenas y no indígenas - el artículo parte de la premisa que las Representaciones Sociales de los no indígenas acerca del desarrollo del turismo en las TI están cargadas de percepciones negativas y estereotipos sobre la organización y capacidad de gestión de los Terena.

Ante esta situación histórica de los Terena en Mato Grosso do Sul, la presente investigación tuvo como objetivo general, identificar las Representaciones Sociales (RS) de los actores sociales involucrados directa e indirectamente con las comunidades Terena, sobre el desarrollo del turismo en las TI ubicadas en Aquidauana/MS. Se parte del postulado que: sujeto, objeto/fenómeno y sociedad son inseparables (Moscovici, 1961), el cual defiende la Escuela Moscovici, cuando señala, el individuo extrae categorías de pensamiento de la sociedad, alimentando su sentido común. Se considera que la teoría de la RS, permite un análisis coherente de las representaciones sociales sobre los Terena y cómo influyen estas representaciones en la visión que tiene la sociedad de Aquidauana de la posibilidad de desarrollo del turismo en las $\mathrm{TI}$.

\section{TURISMO EN TIERRAS INDÍGENAS EN BRASIL}

El turismo indígena está bastante extendido en América Latina. En varios países, como México, Perú, Bolivia y Ecuador, el turismo comunitario es una forma de generar ingresos y valorar los bienes culturales y ambientales presentes en los territorios indígenas, a través de la autogestión y autodeterminación de estos pueblos. Sin embargo, se debe considerar que cada país tiene singularidades internas con respecto a los pueblos indígenas, condicionando el desarrollo del turismo en territorios indígenas (Pereiro, 2013; 2016). En Brasil, por ejemplo, las empresas de turismo comunitario no son comunes, ya que las iniciativas turísticas comunitarias, en comunidades indígenas o no, son usualmente administradas por asociaciones y, con menor frecuencia, por cooperativas. Hay casos en los que las comunidades recurren a empresas privadas asociadas ${ }^{1}$. En cuanto al potencial del turismo en las TI, Brasil emerge por tener una gran sociodiversidad.

Aunque en proporción, Brasil es el segundo país con menor población indígena - solo el $0.4 \%$ de su población es indígena (IBGE, 2010), es a su vez, el país latinoamericano con mayor número de etnias (305) distribuidas en todo su territorio (Comisión Económica para América Latina y el Caribe [CEPAL], 2015). De estas etnias, setenta se encuentran en situación de fragilidad demográfica, en riesgo de desaparición física o cultural, según el documento citado. La diversidad sociocultural indígena brasileña, sumada a los esfuerzos de conservación ambiental de los propios indígenas, por su cosmovisión, formas de vida y de entender y relacionarse con la naturaleza (Gudynas, 2011a), hacen que las $\mathrm{TI}^{2}$ locales estén dotadas de

\footnotetext{
${ }^{1}$ Es el caso de la aldea Coroa Vermelha, ubicada en el estado de Bahía, donde se ha explorado la actividad turística (masiva) desde hace décadas. Los Pataxó reciben turistas de diferentes agencias de viajes y, durante muchos años, se han asociado con una agencia local no indígena llamada Pataxó Ecoturismo (Neves, 2015).

2 Las TI son porciones del territorio nacional, "que luego del proceso ordinario de demarcación administrativa, de acuerdo
} 
activos culturales y ambientales, belleza escénica y diversidad social y ecológica expresiva, contribuyendo a que sean vistas como potenciales atractivos turísticos.

En Brasil, las visitas a pueblos indígenas con fines turísticos se vienen realizando desde hace décadas, si bien que la escala y velocidad con la que el turismo se ha ido extendiendo entre las comunidades originarias y la forma en que estos colectivos buscan asumir la gestión y control de la actividad, es un tema aún significativo (Grunewald, 2015). Sin embargo, hay que considerar que muchas de las comunidades indígenas no pueden desarrollar el turismo, como los pueblos indígenas aislados y las etnias socialmente frágiles o que están involucradas en conflictos socio ambientales violentos (Fundación Oswaldo Cruz [FIOCRUZ], 2020). Además, existen varios casos en los que las comunidades no pretenden desarrollar la actividad turística o, incluso, no pueden recibir turistas debido a la precariedad o falta de infraestructura de acceso o servicios básicos, dificultades lingüísticas, entre otros.

Sobre el turismo comunitario en América Latina, Pereiro (2013) llama la atención al hecho de que, en algunos casos, este turismo está orientado a visitantes extranjeros atraídos por el exotismo indígena y no incluye a la población nacional, que continúa con una mirada colonialista, considerando a los indígenas como pobres, inferiores y con barreras para su desarrollo. Esa es una realidad en muchas TI en Brasil. En comparación con otros países de América Latina, donde el turismo indígena ya se ha consolidado, existen particularidades en Brasil, debido a la legislación indígena, la historia de protección de estos pueblos, la territorialidad y las características de la organización social de esos pueblos, que se articulan y actúan difuso y colectivamente.

En este país, la perspectiva de mejorar la economía mediante el desarrollo de actividades sostenibles y autogestionadas, basadas en la libre determinación es relativamente reciente. Hasta 2015 no existía una regulación de la actividad turística en las TI, lo que debía realizarse a través de la Fundación Nacional del Indio (FUNAI), órgano del gobierno brasileño responsable por las políticas relacionadas con los pueblos indígenas. El marco legal para esta actividad fue la publicación del Decreto Federal No. 5.051/2004, que promulgó el Convenio 169 de la Organización Internacional del Trabajo (OIT) sobre Pueblos Indígenas y Tribales (Decreto No. 5.051, 2004). Fue después de la promulgación del mencionado decreto que el turismo, se convirtió en una de las prioridades en términos de generación de ingresos para las comunidades indígenas brasileñas. Esos documentos y legislaciones llevaron a la publicación de la Instrucción Normativa No. 3/2015, que permitió regular el turismo en las TI, más específicamente, el ecoturismo y etnoturismo, exclusivamente en el modelo de turismo comunitario (Corbari et al., 2017).

El reglamento se limitó al turismo comunitario destinado a evitar la explotación del territorio y de las comunidades por empresas u organizaciones no indígenas. Sobre esto, cabe mencionar, que esta forma de gestión turística surgió en países del Sur global, en los que se produjo un deterioro en la calidad de vida de los pueblos tradicionales. Esto ha ocurrido por limitaciones en las políticas públicas y actividades económicas neoextractivistas, las cuales

con los preceptos legales instituidos, pasa, luego de ser ratificado por Decreto Presidencial para la propiedad de la Unión, habitada por una o más comunidades indígenas, utilizados por ellos en sus actividades productivas, culturales, de bienestar y reproducción física. Por tanto, es un bien de la Unión, y como tal es inalienable e indisponible, y los derechos sobre él son imprescriptibles" (FUNAI, 1996, n. p.). 
presionan los territorios y, no pocas veces, conducen al despojo y desterritorialización, además de profundos impactos ecológicos y ambientales (Palomino-Villavicenzio et al., 2016); turismo en su forma convencional basado en las acciones de grandes corporaciones internacionales (Palomino-Villavicenzio et al., 2016). Las comunidades buscan, ante la presión del capital, encontrar formas alternativas de desarrollo, o más bien, una alternativa al desarrollo, una alternativa a las propuestas hegemónicas de la racionalidad de la economía capitalista (Sampaio, 2005; Gudynas, 2011b), incluido el turismo comunitario.

Según Araújo y Gelbcke (2008, p. 367), “

los principios del enfoque de Turismo Comunitario se centran en la preservación, valorización e inducción de tradiciones y relaciones sociales solidarias, en la generación de trabajo e ingresos basados en la producción asociativa, en la revitalización de los significados de la virtud humana y, finalmente, en el uso adecuado de los recursos naturales y las capacidades humanas locales.

Considerando que el turismo comunitario se refiere a una forma de organización, basada en la autogestión de los recursos patrimoniales comunitarios, en el proceso democrático y solidario de trabajo y distribución de los beneficios generados y en total control de los procesos (Maldonado, 2006; Araújo y Gelbcke, 2008; Cañada, 2010), consideran ese el modelo ideal para las comunidades indígenas en vista de su forma de vida y organización social, basada en el colectivo. Este planteamiento está en línea con lo expuesto por Pereiro (2016), cuando indica que el turismo indígena es parte de un movimiento social, de lucha por el reconocimiento de las diferencias, el control de la tierra, del territorio y del paisaje.

Otro aspecto que debe tenerse en cuenta es que el turismo debe ser una forma de diversificación de ingresos y no de especialización. Los servicios turísticos pueden ser un medio importante de obtención de ingresos, pero no es el único posible, ni necesariamente el más importante, y mucho menos una opción para todos (Cañada, 2010). Cañada (2010) también señala que la demanda no puede expandirse indefinidamente. En el caso de las comunidades indígenas brasileñas, es posible afirmar que su singularidad cultural o la expresividad del paisaje de sus territorios no es suficiente. Para lograr el éxito en el turismo se requieren esfuerzos de planificación y gestión, que incluyen la capacitación y la creación de alianzas, con el apoyo de instituciones públicas y privadas del sector.

\section{EL CONTEXTO DEL PUEBLO TERENA DE AQUidAUNA EN EL PANTANAL SUL-MATO- GROSSENSE}

Aquidauana es un municipio ubicado en el estado de Mato Grosso do Sul y en la región turística del Pantanal, en el Medio Oeste de Brasil. Cuatro TI están ubicadas en el municipio: i) la TI Cachoeirinha (con parte de su territorio ubicado en el municipio vecino, Miranda); ii) TI Limão Verde (ratificada en 2003, pero impugnado por el Tribunal Supremo Federal [STF]); iii) TI Taunay/Ipegue; y iv) la Reserva Indígena (RI) Nossa Senhora de Fátima (con parte de su territorio en Miranda) (ISA, 2020). De estas, las porciones de tierra de las TI Cachoeirinha y RI Nossa Senhora de Fátima ubicadas en Aquidauana no están habitadas, por lo que la población indígena se concentra en las TI de Limão Verde y Taunay/Ipegue.

Cabe mencionar que hay varias áreas en disputa judicial. Existen 17 propiedades rurales que han sido ocupadas, desde 2013, por indígenas que exigen el desalojo de áreas que 
fueron consideradas, por informes antropológicos, como de ocupación tradicional Terena. Esto ocurre, en particular, en las cercanías de los asentamientos de la TI Taunay/Ipegue, dónde hay porciones de lo que se definió como territorio de ocupación tradicional bajo propiedad de grandes terratenientes, lo que genera conflictos constantes por la tierra.

Estas Tl están ubicadas en la llanura pre-Pantanera - una zona de transición entre el bioma Cerrado y el Pantanal -, separados por las montañas de Maracaju. Están habitados por el pueblo Terena (Baltazar, 2010). El lugar de origen del pueblo Terena es el Chaco paraguayo, este hecho se toma como un argumento en discursos político-legales, con el fin de deslegitimar la territorialidad Terena contemporánea, en un movimiento colonialista de negación de los derechos de los indígenas. Como destaca Ferreira (2009), en las impugnaciones a la demarcación de las tierras indígenas, se señala que los Terena 'son originarios de Paraguay' y por ello, la ocupación de los territorios de la margen izquierda del río Paraguay (hoy territorio brasileño) no se podría clasificar en la categoría "tradicional".

Habiendo tenido contacto con personas no indígenas desde el siglo XVI, la forma de vida de Terena fue fuertemente impactada por eventos que marcaron la historia de Brasil. En concreto, hay tres momentos históricos que son fundamentales para comprender la territorialidad y la forma de vida actual de los Terena.

Luego del éxodo, del Chaco paraguayo a la región de Miranda (en las cercanías de Aquidauana), en el siglo XVI los Terena participaron en la Guerra de la Triple Alianza (18641870), conocida como Guerra del Paraguay (Bittencourt y Ladeira, 2000; Baltazar, 2010). A cambio de actuar en defensa de Brasil, los indígenas negociaron la demarcación de tierras con el gobierno, algo que nunca sucedió.

Con el fin de la Guerra, se produjeron varios cambios en la producción socio espacial. Los Terena perdieron la mayor parte de su territorio en disputas con los no indígenas que se asentaron en la región, los cuales, amparados por la Ley de Tierras ${ }^{3}$ (Ley n. 601 de 1850), formaron latifundios destinados a la producción agrícola y ganadera (Bittencourt y Ladeira, 2000), usurpando el territorio tradicional de ese pueblo (Oliveira, 2016).

En el periodo de la posguerra, los Terena reconstruyeron algunos de sus asentamientos, pero muchos individuos comenzaron a trabajar en las fincas que se constituyeron en la región (Baltazar, 2010; Ximenes y Pereira, 2017). Este período es conocido entre Terena como 'tiempo de servidumbre', ya que el trabajo era análogo a la esclavitud (Bittencourt y Ladeira, 2000; Oliveira, 2016; Ximenes y Pereira, 2017). Luego de la formación de los latifundios y la explotación del trabajo, los indígenas fueron despedidos de muchas fincas (Oliveira, 2016). Entonces surgió "un grupo de terratenientes que, aprovechando la influencia obtenida en los gobiernos municipal, estatal y federal, ganó poderes sobre personas y cosas. Así, se estableció un asentamiento ruralista con gran influencia en el Estado brasileño" (Oliveira, 2016, p. 5).

\footnotetext{
3 La Ley de Tierras hizo posible la compra y venta de tierras sin requerir la aprobación del gobierno. Su propósito era promover la colonización y autorizó al gobierno a vender, en subasta, terrenos que no contaban con registro de propiedad, lo que se conoce como terrenos baldíos. En esta categoría se incluyeron tierras pertenecientes a grupos indígenas en las más variadas regiones de Brasil (Bittencourt y Ladeira, 2000).
} 
Otro momento significativo, a finales del siglo XIX y principios del XX, se refiere a que la región comenzó a estar dotada de grandes infraestructuras, como un ferrocarril y una red de telégrafos (Baltazar, 2010). Esta época estuvo marcada por una mayor proximidad entre indígenas y no indígenas, con cambios en los hábitos y costumbres de los Terena, como el cambio de religión (hoy cristianos, en gran parte protestantes), el dominio de la lengua portuguesa, la arquitectura de las casas y otros (Bittencourt y Ladeira, 2000; Acçolini 2007).

En el siglo XX, a través del extinto Servicio de Protección Indígena (SPI) y su reemplazante, FUNAI, los pueblos recibieron mejoras en la infraestructura, como trazado de calles, electricidad, alumbrado público y otras, con el objetivo de 'emancipar' el indio (Baltazar, 2010). Como señalan Ximenes y Pereira (2017, p. 28), esta historia expresa, por un lado, "las estrategias y el protagonismo Terena para garantizar al menos una parte del territorio tradicional. Por otro lado, muestra que el proceso de colonización estuvo acompañado de la ocupación del territorio indígena".

Aunque fuertemente influenciado por la forma de vida y por la cultura no indígena, hay elementos que demuestran que la cultura Terena se reinventó a lo largo de los siglos. Aspectos como la existencia de "chamanes" que se ocupan de la medicina natural (Acçolini, 2007); tradiciones como la "danza pau-pau", que representa la dualidad de la personalidad, elementos estructurales de la cosmología Terena; el hecho de que aún sean hablantes de la lengua Terena (Cardoso, 2004); artesanías poco influenciadas por técnicas más recientes; y la forma de vida misma, demuestran que "ser indígena" no se puede simplificar con una perspectiva eurocéntrica y colonialista.

La situación de los Terena es de lucha constante por la garantía de su territorio tradicional, evidenciado por el proceso de retoma de tierras. Como se puede apreciar en el documento final de la X Gran Asamblea del Pueblo Terena, 2017, la reanudación no fue una mera lucha por la tierra, sino un proceso de reterritorialización, que pasa por un conflicto socio-ambiental donde el Estado tiene un papel expresivo. En el citado documento, se puede verificar esta afirmación, cuando se destaca que "hoy ya no tenemos solo un banco ruralista, sino un gobierno ruralista, porque las fuerzas del agro-bandidismo se apoderaron de la estructura del estado [sic] que lo maneja solo para sus intereses" (Conselho do Povo Terena, 2017, n. p.).

Figura 1. Jóvenes con trajes típicos

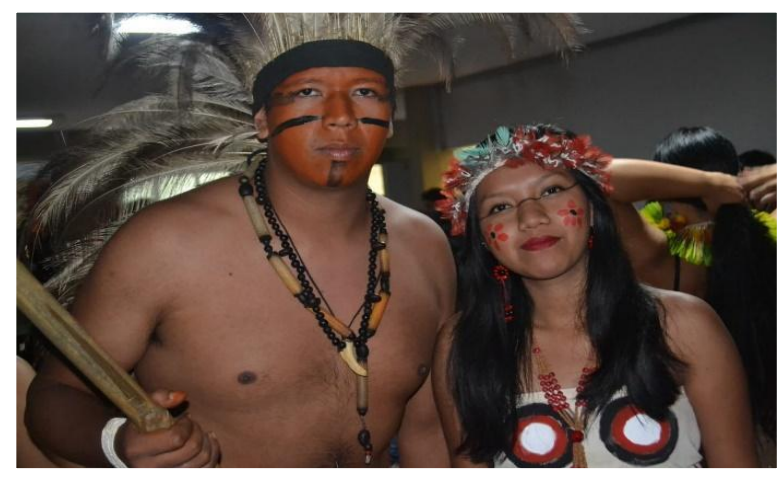

Fuente: UFMS, s. d. 
Figura 2. Piezas de cerámica tradicional Terena

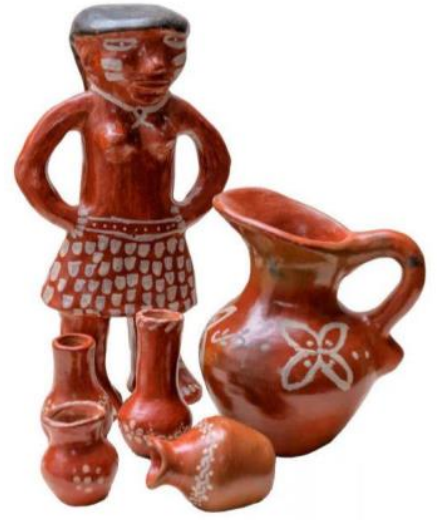

Fuente: Paiol (s. d)

La principal fuente de sustento actual de estas comunidades es la agricultura a pequeña escala, la explotación avícola y de cerdos a pequeña escala. En mayor medida está la ganadería, aunque también es un inductor de conflictos internos por el cierre de áreas de uso colectivo para fines privados. Además, debido a la historia de interacción con los no indígenas, es habitual el trabajo temporal en las fincas de la región o en los centros urbanos cercanos (FUNAI, n. d.).

El turismo, sin embargo, no es una actividad económica en los pueblos de Aquidauana. Cabe mencionar que la primera propuesta para el desarrollo del turismo basado en el empoderamiento de los indígenas Terena en TI se realizó a través de un proyecto de extensión en la Universidad Federal de Mato Grosso do Sul (Campus Aquidauana) (UFMS, 2018). A partir de 2015, con la publicación de la Instrucción Normativa no. 3 la actividad turística de FUNAI comienza a desarrollarse a través del turismo comunitario en diferentes territorios indígenas de Brasil. Con la oportunidad de publicación por parte de un organismo gubernamental oficial y liderazgo indígena en otros territorios indígenas de Brasil, se inició la capacitación para el Terena, en vista del relativo potencial turístico de las TI ubicadas en el Pantanal del Mato Grosso do Sul.

El curso tuvo como objetivo despertar y fomentar la actividad turística en las TI de Aquidauana, Miranda y Dois Irmãos do Buriti (municipios vecinos). El proyecto contó con la participación de líderes e indígenas de diferentes pueblos de la región. En el desarrollo del proyecto se percibió el interés de los pueblos indígenas por el turismo como una alternativa para la valorización de la cultura, el desarrollo social, la preservación ambiental y de desarrollo económico a través de la generación de empleo, trabajo e ingresos, de cara a unas pocas opciones de actividades laborales e inserción social en la región, especialmente para los jóvenes. Sin embargo, estas comunidades necesitan apoyo y capacitación para postular el inicio de la actividad a través del turismo comunitario.

En este momento, la interrelación con el turismo se da a través de la venta de artesanías, siendo esta una actividad laboral marginal y común a varios pueblos indígenas de Brasil. La artesanía fue también la única opción de inclusión previa de los indígenas en la actividad turística en el período en el que la empresa Serra Verde Express, operadora de trenes 
turísticos en Brasil, restableció una línea ferroviaria que no se utilizaba para el turismo hasta entonces y puso al Turista Tren en circulación del Pantanal. Este tren operaba en el tramo de Campo Grande a Miranda, con parada en el distrito de Taunay, donde se ubica TI Taunay/Ipegue. En la parada, Terena intercambió artesanías y alimentos y bebidas (Souza et al., 2015). Sin embargo, el tren dejó de operar en 2014 debido a numerosos factores, entre ellos el largo recorrido del tramo y la reducción de la demanda turística.

La región - 'puerta de entrada' del Pantanal -, tiene como principal atractivo 4 las fincas, áreas privadas de ganadería extensiva, que tuvieron inserción del turismo ecológico a partir de la década de 1990 (Rocha Filho, 2010). Actualmente el turismo en Aquidauana está restringido a las posadas del Pantanal que organizan diversas actividades dentro de su espacio definido como: observación de vida silvestre (safaris fotográficos y turismo del jaguar), paseos en bote, cabalgatas, caminatas y recientemente, la creación de un producto turístico basado en el turismo de experiencias. Con la participación de turistas en las comitivas pantaneras (transporte de ganado de una zona de pasto a otra, pasando por llanuras inundadas, puentes, ríos, caminos de terracería y otros paisajes, muchas veces con pernoctaciones en forma de campamento y encuentro con animales que habitan en el Pantanal). El turismo en las posadas pantaneras, con excepción de la pesca, se basa en un modelo de confinamiento del turismo como si estuvieran en resorts en fincas pantaneras, donde no existe interacción entre el turista y la población local, incluidas las comunidades indígenas y ribereñas del Pantanal. La presencia del turismo ecológico dentro de las áreas de producción demuestra que el turismo en Aquidauana está guiado por tendencias tradicionalistas y, por lo tanto, el turismo en TI podría representar un cambio de paradigma. El primer diagnóstico del potencial turístico realizado con las Terena identificó que los segmentos de turismo cultural (etnoturismo), ecoturismo (turismo de observación de aves y fauna, trekking por senderos, montañismo, cabalgatas y turismo aventura) y turismo de pesca serían las opciones más viables a diseñar, a través del turismo comunitario.

Este es el modelo idealizado para el desarrollo de las TI, dada su particularidad, desde la oportunidad hasta la participación comunitaria, la autogestión y la autonomía, principios que también demandan los pueblos indígenas en sus territorios.

\section{DISEÑO DE LA INVESTIGACIÓN}

Para llevar a cabo esta investigación, se optó por un camino metodológico basado en el estudio de los fenómenos sociales a través del sesgo de la psicología social de Moscovi (2003). El estudio de Moscovici, iniciado en 1961, emerge en la perspectiva crítica sobre el pensamiento hegemónico y tradicional de la época, que concibió separar al sujeto (actor social) de su realidad social. Según Moscovici (2012, p. 27), las RS se definen como "una modalidad de conocimiento particular, que tiene la función de elaborar comportamientos y comunicaciones entre los individuos". En este sentido, los estudios sobre RS se centran en comprender el funcionamiento del pensamiento cotidiano sobre los objetos, las personas y los eventos que vive la sociedad. En su teoría sobre la RS, Moscovici (2003) se dedicó a comprender el sentido común diseminado en las comunicaciones e interacciones entre

\footnotetext{
${ }^{4}$ Un segundo atractivo que se ha ido consolidando en Aquidauana es la Estrada Parque Piraputanga, región de transición entre el bioma Cerrado y el Pantanal, pasando por la Serra do Maracaju. El potencial turístico de esta región está relacionado con el turismo de pesca deportiva, el cicloturismo, el turismo gastronómico, el turismo de aventura y el turismo ecológico.
} 
diferentes actores sociales. Moscovici $(1961 ; 2003)$ sostiene que, estas representaciones se construyen y difunden a través de la interacción pública entre actores sociales, y también agrega, que ello se hace posible en las prácticas comunicativas cotidianas. Es el estudio y la valoración del sentido común, es decir, cómo los actores sociales tienen su representación construida sobre determinados objetos o fenómenos. Alexandre (2004, p. 127) también respalda que el sentido común "está socialmente elaborado y funciona en el sentido de interpretar, pensar y actuar sobre la realidad". Moscovici (1961) expone la necesidad de interpretar científicamente las representaciones de sentido común sobre un objeto, personas o eventos, analizando el contexto en el que se construyen y se originan.

La necesidad de comprender la evolución del sentido común tiene como objetivo estudiar la "objetivación" y el "anclaje" fundamentación de las representaciones que se miden y se hacen posibles en la sociedad, en su espacio y en la vida cotidiana. Moscovici $(2003$, p.78) entendió que la objetivación "se dirige hacia afuera (hacia otros) toma de allí conceptos e imágenes para acercarlos y reproducirlos en el mundo exterior, para dar a conocer las cosas a partir de lo ya conocido". Anclar, en cambio, "mantiene la memoria en movimiento y la memoria se dirige hacia adentro, es siempre colocar y quitar objetos, personas y eventos que clasifica según un tipo y los etiqueta con un nombre" (p. 78).

En este sentido, es necesario comprender el contexto espacio-temporal, en el cual se conciben las representaciones, las mismas son dinámicas y tienen la capacidad de cambiar y alterar el pensamiento de diferentes grupos sociales (Jodelet, 2001). Guareschi y Jovchelovitch (1994, p. 20) tienen cierta aprehensión de cómo se forman las RS, destacando que estas "se forman cuando las personas se encuentran para hablar y discutir la vida cotidiana o cuando están expuestas a instituciones", y todavía sostienen que este proceso puede estar vinculado "a los medios de comunicación, a los mitos y al patrimonio cultural e histórico de su sociedad" (p. 20).

Jodelet (2001) y Moscovici (2003) demuestran, que la comunicación es de suma importancia para que la RS no se quede estática, dado que en su vida cotidiana y vivencias los actores sociales reproducen, formulan y modifican sus ideas, creencias, valores, imaginario y sus acciones.

Cabe destacar que los RS tienen ciertas funciones; para Morera et al. (2015, p. 1160) "RS es un reflejo de las relaciones complejas, reales e imaginarias, objetivas y simbólicas que el sujeto mantiene con el objeto". Un ejemplo de esto está en la teoría de los campos de Bourdieu (1983), en el cual discute las luchas simbólicas entre actores sociales en distintas posiciones en un juego político, donde cada grupo tiene una RS diferente ante un sistema político vigente. Morera et al. (2015, p. 1160), señalan que, en RS la función primaria "es la aprehensión y control de la realidad, permitiendo su comprensión e interpretación".

Así, desde la década de 1970, han surgido numerosas investigaciones basadas en la teoría de RS de Moscovici. Cardoso y Gomes (2000) señalan que, los estudios se destacan en psicología social (Moscovici, 1976); en antropología, postulado en términos de salud (Willians, 1990; Good y Good, 1993); en sociología (Herzlich, 1992; Adam y Herzlich, 1994; Morris, 1998); y en la historia (Chartier, 1990). Los estudios relacionados con RS sobre el medio ambiente también tuvieron un crecimiento acelerado con la crisis ambiental, en la que se puede 
destacar a Reis y Bellini (2011) quienes presentan los estudios de Reigota (2002), Trevisol y Socolovski (2000) y Trevisol (2004). La investigación sobre las RS en el turismo es reciente y ha ganado protagonismo desde la década de 1990 con diferentes estudios en Latinoamérica y Europa, como los trabajos de Ferreira (1995) y Costa y Sanaglio (2014).

A partir de las RS y su función, la investigación surgió con el propósito de identificar las RS de los actores sociales, vinculados directa o indirectamente al sector turístico de Aquidauana, con los Terena y con el desarrollo del turismo en las TI.

Además, lo que motivó la investigación, fue el hecho de que Aquidauana y los municipios aledaños tienen una gran cantidad de poblados Terena, sin embargo, no forman parte del Proyecto Turístico Pantanal. Para la realización de esta investigación, se eligieron diferentes procedimientos metodológicos durante este trabajo, incluyendo la investigación bibliográfica en fuentes primarias y secundarias, entrevistas abiertas y no estructuradas, visitas a los pueblos de las TI Limão Verde y Taunay/Ipegue y a las áreas ocupadas ${ }^{5}$, donde tuvo lugar la observación directa no estructurada.

Finalmente, se utilizaron entrevistas semiestructuradas con actores sociales directa o indirectamente involucrados en la actividad turística del área urbana y rural del municipio de Aquidauana, incluyendo comerciantes, artesanos, docentes, empresarios turísticos, estudiantes, políticos, agricultores y gestores públicos de turismo.

\section{SELECCIÓN DE MUESTRAS Y TÉCNICA DE DISCURSO COLECTIVO DE SUJETOS}

Las entrevistas se realizaron con actores sociales que tienen conexiones con los pueblos indígenas en su vida cotidiana y conocimiento de la forma de vida y cultura de los Terena. En búsqueda de RS se eligió una muestra intencional donde, de un número $(x)$ de entrevistados, se alcanzaría la saturación de datos, es decir, se pudo demostrar las mismas respuestas, definiendo la RS de esa sociedad. En este sentido, se alcanzó un total de nueve informantes, ya que se encontró que las respuestas tenían la misma RS sobre la Terena de Aquidauana. La entrevista consistió únicamente en un interrogatorio abierto para que se pudiera abrir un diálogo con el entrevistado. Así, las entrevistas se basaron, de manera sencilla y objetiva, en la siguiente pregunta: "¿cree que sería factible un proyecto de desarrollo turístico en Tierras Indígenas de Aquidauana?" y según la respuesta, los autores podrían hacer otras preguntas a los entrevistados.

Para el análisis de los datos e identificación cognitiva de los entrevistados sobre la RS, se utilizó la metodología de análisis del Discurso del Sujeto Colectivo (DSC), de Lefèvre y Lefèvre (2003). Estos autores mencionan que el sujeto, en su vida diaria, emite juicios, opiniones y otras formas de expresar RS. El sentido común es una forma de conocimiento, de experiencia, compartida y elaborada socialmente, basada en una realidad que significa la visión de un grupo social. La técnica DSC permite analizar todos los testimonios, que es el punto clave para identificar las RS, donde se encuentran primero las Ideas Centrales (IC), luego las Expresiones Clave (ECH) y, finalmente, el discurso de síntesis, que representa el DSC Según

\footnotetext{
5 El turismo no se puede desarrollar en las áreas en litigio, primero por la falta de propiedad del área, segundo por la seguridad de los visitantes. La propia regulación turística (Normativa 003/2015) destaca que, en áreas donde exista una amenaza a la integridad de los visitantes, la práctica turística no será autorizada.
} 
Lefèvre y Lefèvre (2003), después de difundir el discurso en su totalidad, es posible identificar las $\mathrm{ECH}$, pequeñas partes del discurso principal, que tiene el centro del contenido exteriorizado por el entrevistado. Posteriormente, surge la $\mathrm{ECH}$ o $\mathrm{Cl}$ con un discurso, cuya función es demostrar, describir y nombrar con precisión la singularidad y homogeneidad de la comunicación.

En las pequeñas secciones de la ECH se pueden visualizar un número ilimitado de IC, que luego contribuyen a la construcción del discurso de síntesis a través de la DSC. La combinación de varios DSC demuestra la RS sobre un fenómeno u objeto, y puede medirse como la idea de lo que se difunde en la sociedad. Según Lefèvre et al. (2009, p. 2), "el discurso del sujeto colectivo, por sus características, se abre, en cuanto a las representaciones sociales como objeto de investigación empírica", y también complementan, informando que, "en caso de diálogo - entre todos y las partes, entre lo individual y lo colectivo, entre lo teórico y lo empírico, entre el paradigma y la frase, y por último, pero no menos importante", una herramienta moderna e intensa para comprender las complejidades del mundo actual. Esta metodología ayuda a analizar, en este contexto, las diversas dimensiones de los conflictos entre grupos en diferentes posiciones en un juego bourdieusiano. El ejemplo que se muestra en el Cuadro 1 fue extraído de una RS a través del DSC, del discurso de un entrevistado del sector turístico Aquidauana sobre el desarrollo del Turismo en Tierras Indígenas.

\title{
Cuadro 1. Representaciones sociales a través del discurso del sujeto colectivo
}

\begin{abstract}
Discurso
Creo en el potencial del turismo indígena en Aquidauana debido a la gran cantidad de pueblos y pueblos indígenas. La cultura indígena no es explotada por el turismo en el estado de Mato Grosso do Sul y mucho menos en Aquidauana. El problema es que existe una gran cantidad de conflictos y disputas por tierras en el municipio. Los conflictos ya han provocado luchas armadas, violencia e incluso muertes en la región de Taunay. Los ganaderos dicen que han sido herederos de la tierra desde finales de 1800 . Tienen documentos antiguos y nadie sabe si fueron obligados a ocuparlos en ese momento. Los antropólogos han encontrado rastros de cementerios indígenas y han emitido informes de que son tierras de Terena, ya que sus antepasados descansan en esas tierras. La pelea ya está en Brasilia y tiene toda esta repercusión porque los ganaderos dominan todo en la ciudad y tienen mucha influencia política. Son explotaciones con infraestructuras que han sido reocupadas y traen pérdidas económicas. A menudo los indígenas saquean todo en la ocupación de las fincas, despertando cada vez más resentimientos negativos. Creo que cuando se resuelva este impasse, el turismo relacionado con los indígenas podrá desarrollarse sin problemas, ya que el turismo de naturaleza es muy caro y atrae solo a turistas con alto poder adquisitivo. Ahora, los Terena dependen en gran medida del gobierno y otros organismos como las universidades. Si no tienen espacio es muy difícil desarrollarse, ya que necesitan apoyo constantemente. Son muy hospitalarios y alegres, esto es de gran valor, pero se les desprecia por trabajar en la ciudad. No hay trabajo en los pueblos. La salud y la educación son precarias. Ahora, no sé cómo vamos a trabajar juntos en el turismo indígena. Espero que lo hagan, porque veo cuánto sufren y son discriminados aquí en la ciudad.
\end{abstract}




\begin{tabular}{|c|c|}
\hline Expresión-clave & Idea Central \\
\hline $\begin{array}{l}\text { * creo en el potencial de las TI } \\
\text { * la cultura indígena no es explorada por el turismo } \\
\text { * gran número de conflictos y disputas por la tierra } \\
\text { * luchas armadas e incluso muertes } \\
\text { * los ganaderos dicen ser herederos de las tierras } \\
\text { * presentan documentos antiguos } \\
\text { * los antropólogos han encontrado rastros de } \\
\text { cementerios } \\
\text { * los ganaderos dominan todo en la ciudad } \\
\text { * en influencia política } \\
\text { * fincas con infraestructura } \\
\text { * los indígenas se aprovechan de todo } \\
\text { * creo que cuando se resuelva este impasse se podrá } \\
\text { resolver el turismo en TI } \\
\text { * los Terena dependen mucho } \\
\text { * necesitan apoyo constantemente } \\
\text { * son hospitalarios y felices } \\
\text { * son despreciados por trabajar en la ciudad } \\
\text { * en los pueblos no hay trabajo } \\
\text { * la salud y la educación son precarias } \\
\text { * no sé cómo vamos a trabajar juntos en turismo } \\
\text { indígena. } \\
\text { * sufren y son discriminados aquí en la ciudad }\end{array}$ & $\begin{array}{l}\text { Perspectiva del futuro } \\
\text { Oferta turística } \\
\text { Conflictos territoriales } \\
\text { Dominación y manipulación (juego) } \\
\text { Dependencia del Estado } \\
\text { Hospitalidad } \\
\text { Trabajo, salud y educación } \\
\text { Falta de conocimiento sobre TI } \\
\text { Discriminación }\end{array}$ \\
\hline \multicolumn{2}{|l|}{ RS del DSC } \\
\hline \multicolumn{2}{|c|}{$\begin{array}{l}\text { Creo en el potencial de las TI. Hay mucho que explorar, pero los conflictos por disputas por la tierra en la región } \\
\text { deben resolverse primero. Los ganaderos dominan y manipulan el juego político por la disputa por la tierra. Los } \\
\text { Terena dependen en gran medida del apoyo de políticas públicas del Estado para el trabajo, la salud y la } \\
\text { educación. No sé cómo vamos a trabajar juntos en TI. }\end{array}$} \\
\hline
\end{tabular}

Fuente: Elaboración propia a partir Lefèvre (2003). Entrevista concedida a los autores (2020)

El discurso presentado tiene una RS sobre los Terena de Aquidauana. En el $\mathrm{Cl}$ del discurso del Cuadro 1 se destaca la perspectiva futura del potencial turístico y la oferta relacionada con los pueblos indígenas; conflictos entre agricultores e indígenas, relacionados con la disputa por la tierra; el juego bourdieusiano de los dominantes en el territorio con sus influencias políticas y su manipulación; a las dependencias de políticas públicas de los Terena; valorar la hospitalidad; discriminación y desconocimiento de las tecnologías de la información por parte de los actores sociales del sector turístico. A partir de esta muestra y técnica, se realizaron análisis de datos y discusión de resultados.

\section{ANÁLISIS DE DATOS Y DISCUSIÓN DE RESULTADOS}

Una vez finalizadas las entrevistas, se elaboró el cuadro 2, que contiene el resultado del DSC, luego de analizar la expresión clave y las ideas centrales.

Cuadro 2. RS acerca del desarrollo del turismo en las TI de Aquidauana

\section{RS del DSC}

Los indígenas viven de la ayuda del gobierno y consumen cuando tienen dinero. No les gusta trabajar y el voto es moneda de cambio. No creo en el proyecto de turismo indígena.

Ya llevé turistas a visitar los pueblos indígenas, pero no funciona porque viven borrachos. Terminé las visitas porque había acoso a los turistas. No les gusta trabajar y solo quieren invadir tierras. 
No va a funcionar. No les gusta estudiar y trabajar. Estudian gracias a la beca del Gobierno Federal. Usan el dinero para comprar el teléfono celular más moderno.

Conocemos el potencial del turismo en los pueblos, pero no tenemos personal para los proyectos. Es muy complicado trabajar con los indígenas, que siguen pidiendo de todo. No hay contrapartida ni retorno de la inversión en estos proyectos.

No funciona. Solo quieren saber cómo invadir la tierra de otros y no hacer nada con ellos.

Están en la mejor tierra y están acomodados. Los demás continúan invadiendo tierras de familias tradicionales. No les gusta trabajar y viven borrachos. Dudo que el turismo funcione.

Si quieres desarrollar el turismo, tendrás que hacerlo todo tú mismo y capacitar a los indígenas. Muchos solo quieren beneficiarse y solo piensan en política. No sé por qué hay tanta tierra demarcada si no la usan. ¿Dónde está el dinero para tanta política?

Los indígenas solo hacen lo que les interesa. La mayoría de las becas son para estudiantes indígenas y el monto es el doble del resto de becas. El turismo no existe aquí, ya que solo los agricultores se benefician de la actividad. Solo veo conflictos por la tierra.

Solo veo invasión de tierras y consumo por parte de estudiantes en las tiendas. Solo se dedican a vender verduras, pero la gente tiene miedo de comprar. No veo a ninguno de ellos trabajando.

Fuente: Elaboración propia a partir Lefèvre y Lefèvre (2003)

El foco de las entrevistas fue buscar la RS sobre el desarrollo del turismo en las TI. Sin embargo, los discursos de los entrevistados en muchas ocasiones cambiaron el tema y exteriorizaron los conflictos existentes y el poder en el territorio. Estas RS fueron incorporadas al presente manuscrito, ya que se entiende que el turismo no es histórico y apolítico, no es una actividad económica neutral, sino con relaciones de poder desiguales. Está estructurado y estructurado con base a un sistema económico y social más amplio. Este panorama debe ser tenido en cuenta en las reflexiones sobre el desarrollo o no desarrollo del turismo en un territorio determinado.

En la evidencia destacan el racismo estructural y otros estereotipos sobre los Terena de Aquidauana. De esta manera, RS tiene una intensa carga ideológica, donde se manifiesta el racismo velado que han sufrido los pueblos indígenas desde la llegada de los europeos al territorio brasileño. En este sentido, la lectura histórica sobre los pueblos indígenas suele configurarse por la falta de flujos de información y desinformación, lo que lleva a la población no indígena a reducir a los pueblos indígenas a estereotipos que no se corresponden con la realidad (Lima y Almeida, 2010; Bessa Freire, 2016; Milanez et al., 2019). Cabe señalar que estos flujos de desinformación suelen ser promovidos por actores sociales que ostentan el poder político y económico, que quieren la deslegitimación étnica y territorial de estos pueblos.

Estas estrategias se utilizan para asumir posiciones en el juego entre dominantes y dominados. Bourdieu (2002, p. 27) sostiene que los campos "son lugares de relaciones de fuerzas que implican tendencias y probabilidades objetivas. Un campo no está orientado por el azar". Cada campo emana autonomía y manifestaciones de poder y estas se ponen en juego para lograr los objetivos propuestos. Este poder enmascarado se presenta en un discurso ideológico, el cual domina los valores hasta el punto de que, muchas veces, la sociedad no sospecha que es inducida a aceptar, sin duda, un determinado conjunto de valores (Mészáros, 1989).

En cuanto a las entrevistas realizadas, la opinión de que los Terena son asistidos por el Estado, el cual les brinda subsistencia económica, se evidencia a través de las becas 
académicas, resultado del programa Bolsa Permanência del Ministerio de Educación (MEC). Cabe señalar que esas becas, instituidas en 2013, tienen como objetivo posibilitar la permanencia en la carrera de estudiantes en situación de vulnerabilidad socioeconómica, incluso indígenas y quilombolas; reducir los costos de mantenimiento de las vacantes como resultado de la deserción de los estudiantes y promover la democratización del acceso a la educación superior (Portaría n. 389, 2013). Esta asistencia contribuye a que la educación superior brasileña tenga mayor igualdad de acceso $y$, principalmente, permanencia. Al desencadenar el hecho de que los Terena reciban becas -y ese sería el motivo de su interés por ingresar a la universidad-se deslegitima la capacidad intelectual y la buena voluntad de estos individuos para tener una educación superior. Además, aunque de forma inconsciente, busca demarcar la universidad como un espacio de élite, restringido a determinados grupos y clases sociales.

Aún sobre la ayuda recibida por los Terena, se induce a que el monto de la ayuda recibida se gaste en el comercio de Aquidauana, incluida la compra de efectos electrónicos, al mismo tiempo que los indígenas estarían "invadiendo" tierras, donde no "producen". Así, la RS demuestra la existencia de una opinión generalizada, acerca de la incoherencia de permitir que los indígenas adquieran productos tecnológicos o incluso artículos de primera necesidad, con la ayuda recibida del Estado. Al respecto, Milanez et al. (2019) denominan "fosilización de las culturas indígenas" ${ }^{\prime}$. Ser indígena implica no adquirir y utilizar artefactos de la civilización occidental.

Además, imponen a los indígenas una imagen de "gente holgazana", porque, en su opinión, no producen. Este es uno de los puntos principales de la RS que aquí se presenta y cómo los pueblos indígenas son entendidos por una parte de la población no indígena brasileña. Por tener una forma de vida diferente, proveniente de tradiciones no capitalistas y, por lo tanto, no apuntando a la acumulación de capital, los indígenas son entendidos como holgazanes. No se consideran formas legítimas de valoración de la naturaleza y la sociabilidad, que no están marcadas por lógicas centradas en la productividad, el control y el uso irrestricto de la naturaleza. Como no otorgan a las TI la condición de tierra "productiva" - es decir, donde se practica la producción extensiva - se deslegitima el hecho de que estas personas demanden las áreas consideradas para uso tradicional. Cuando se afirma que los Terena, "solo quieren invadir tierras", se demuestra que existe un desconocimiento, derivado de un flujo de desinformación, sobre por qué estas personas reclaman la propiedad de las fincas aledañas a las aldeas.

Lo entienden como una invasión, cuando en realidad, se trata de una "reconquista de tierras", un regreso a las áreas que forman parte de un territorio tradicional, de donde fueron expulsados. Estas acciones, que no son exclusivas de esta etnia, han generado conflictos por la tierra, los cuales muchas veces culminan con la muerte de líderes indígenas (Oliveira, 2016; FIOCRUZ, 2020), ampliamente denunciados ante organismos internacionales. Como otros pueblos indígenas en Brasil, fueron expulsados de sus territorios tradicionales, y las demarcaciones realizadas a lo largo de los años, no consideraron las tierras apropiadas

\footnotetext{
${ }^{6}$ En cuanto a la fosilización de las culturas indígenas, cabe señalar que, por un lado, se intenta deslegitimar al indígena, por otro, hay una romantización del indio. La idea de una vida social y política idílica es ingenua y paradójica, ya que las propias comunidades indígenas también han colonizado el espacio y el paisaje, lo que a su vez tiene consecuencias sociales.
} 
indebidamente por los no indígenas, confinando a los Terena en una pequeña parte de sus territorios originales (FIOCRUZ, 2020, n. p.). Esto está en línea con lo expuesto por Oliveira (2016), que varios actores sociales - incluido el Estado - utilizan los más variados sofismas para distorsionar la realidad y formar una opinión pública contraria a la regularización de las TI.

La búsqueda de consensos sobre la verdad es recurrente en los conflictos socioambientales, en los que prevalecen ciertos actores sociales, porque acceden y movilizan el poder político y económico para crear una "verdad" y, así, orientar el uso y la producción del espacio, con el apoyo de parte de la población (Robbins, 2012). Este tema es conocido por los Terena, como se puede apreciar en la carta de la Asamblea del Pueblo Terena de Taunay/Ipegue (Conselho do Povo Terena, 2011), publicada por el Consejo Misionero Indigenista (CIMI), en la que se expone que "las situaciones de racismo y discriminación han sido recurrentes. Muchas campañas de desinformación e intimidación han sido, en gran parte, realizadas por sectores los cuales se oponen a las demarcaciones", y que aproximadamente 10.000 indígenas trabajan para cortar caña de azúcar en los cultivos de Mato Grosso do Sul, porque no pueden trabajar en sus tierras. "Si eso no fuera suficiente, hay muchas afirmaciones racistas de que 'el indio no trabaja'” (CIMI, 2011, n. p.).

Esta situación tiende a agravarse debido a los recientes reveses políticos en Brasil, con el auge de la extrema derecha al poder y, en consecuencia, el mayor empoderamiento de grupos que atentan contra los derechos fundamentales de los pueblos y comunidades originarias (Oliveira, 2016). Esto se aprecia en la Carta Ipegue de 2019, cuando señala:

Pasamos por el gobierno llamado izquierda, que se rindió al capital; resistimos al gobierno golpista, que destrozó nuestros derechos y ahora estamos listos para hacer una resistencia fuerte al gobierno de extrema derecha, anti indígena, racista y autoritario del presidente Jair Bolsonaro. (Conselho do Povo Terena, 2019, n. p.)

Otro aspecto presente en las RS es el alcoholismo. De hecho, es tema recurrente cuando se trata de pueblos indígenas en Brasil y realmente ha alarmado a investigadores, organizaciones sociales e instituciones de salud, como lo destacan Guimarães y Grubits (2007). Sin embargo, el tema no debe abordarse de manera superficial, ya que implica explorar los valores culturales, el proceso histórico y la corriente sociopolítica de cada grupo social, como lo puntualiza Langdon (2001, p. 84) "lo que es beber, cuánto beber y cómo beber varía de un grupo a otro". De hecho, el alcohol fue uno de los instrumentos utilizados por los blancos para el dominio y destrucción de las sociedades indígenas (Langdon 2001; Acçolini, 2007), sin incluir el uso de bebidas fermentadas tradicionales, prácticas culturales de diferentes etnias (Langdon 2001; Guimarães y Grubits, 2007).

En cuanto a los Terena, Langdon (2001) señala que, esta etnia tiene una tasa global de $17,6 \%$ de alcohólicos, la cual es entre el 5 a $6 \%$ superior a la tasa de los brasileños no indígenas. Sin embargo, no es el propósito de este artículo discutir la historia del alcoholismo entre los Terena. Se llama la atención sobre el consumo de alcohol (y no la dependencia) como un argumento utilizado para deslegitimar la capacidad de estos indígenas, como se puede apreciar en frases como "lo que más tiene es bar para borrachos. ¿Cuál turismo?" y "lo que me propones, ya lo probé y no funciona, porque viven borrachos". Vale la pena reflexionar 
sobre sí, de esta manera, se cuestiona también la capacidad de los no indígenas cuando son consumidores de drogas como el alcohol.

Por otro lado, llama la atención el hecho de que este problema social y de salud no puede ser desatendido, pues tiene un impacto social negativo y en la salud de estas comunidades. En el informe de un entrevistado, que ha trabajado organizando visitas turísticas a estos pueblos, se puede constatar uno de los impactos negativos del consumo de alcohol "[...] un día, en una charla, los indígenas se emborracharon y acosaron a unos turistas. Esto sucedió en otras dos ocasiones y desde entonces tomé la iniciativa de terminar las visitas". Así como se debe proceder con respecto a las reglas de comportamiento, las cuales deben establecerse y negociarse desde el principio, en la etapa de la preparación de la comunidad para recibir turistas. Esta es una de las razones que los actores sociales involucrados con el turismo indígena necesitan conocer y comprender, la dinámica sociocultural de cada grupo étnico; estas particularidades del comportamiento deben ser previamente aclaradas con las comunidades, para que pueda manifestarse una relación de respeto mutuo: turista- población indígena residente.

Estos son los principales aspectos de la RS presentadas y están relacionados con el turismo, por ello existe incredulidad en la capacidad de los Terena para gestionar un proyecto turístico en las TI. Esta incredulidad está ligada, precisamente, al hecho de que los Terena viven de supuestas ayudas y que no tienen la formación ni la voluntad para desarrollar el turismo.

En este sentido, los discursos, en diferentes formas y contenidos, exteriorizan RS exclusivas sobre una etnia, difunden por la comunicación, la interacción social en sus diversas facetas y originan nuevos conflictos, que se evidencian en la sociedad brasileña general. Fernandes y Souza (2015, p. 104) argumentan que "las representaciones que prevalecen están construidas por narrativas hegemónicas, capaces de representar a un grupo social en detrimento del otro". Los autores también agregan que "estas representaciones se construyeron a través de la perspectiva eurocéntrica, que instituye significados de normalidad y anormalidad como norma estándar, el hombre blanco, heterosexual y cristiano" (p. 104).

Existe un vínculo con la "productividad" de la tierra, que parece estar relacionada a la producción y explotación extensiva del suelo y los recursos naturales, como es el caso de la ganadería extensiva y la agricultura a gran escala. Las TI fueron "descritas incluso por algunos presidentes de la FUNAI como 'no productivas', como contrarias a los intereses de la sociedad brasileña" (Milanez et al., 2019, p. 2171). Un territorio o forma de vida, que no se asemeja al proyecto de desarrollo basado en la producción de commodities, no parece estar validado como un uso legítimo de la tierra.

Es de destacar, que ninguno de los entrevistados presentó argumentos relacionados con una posible caracterización errónea o pérdida de identidad de los Terena, cuestionando si son "verdaderos indios". Estos son hechos importantes, pues este es un aspecto muy común en los discursos sobre los pueblos indígenas: la "autenticidad" de estos pueblos, como puede verse en Lima y Almeida (2010), Castro (2006), Bessa Freire (2016) y Milanez et al. (2019). Además, no se cuestiona, ni se contradice el potencial turístico de las $\mathrm{TI}$, ya sea en términos 
de aspectos socioculturales o en lo que se refiere a los atractivos naturales de los propios territorios.

También se observa, que la incredulidad está vinculada al perfil histórico del turismo en el municipio, el cual se ha basado en la explotación de la ganadería extensiva, con la incorporación del turismo ecológico de forma aislada y los balnearios en algunos sectores de sus ríos, sin tener contacto con comunidades originarias. Como ya se señaló, el turismo en esa región se centra en estas actividades, lo que lleva a pensar que las alternativas propuestas, no son viables o difíciles de implementar. Sin embargo, en los últimos años se ha incrementado el número de indígenas en los espacios académicos, que buscan alternativas para el desarrollo de territorios demarcados.

\section{CONSIDERACIONES FINALES}

Las TI ubicadas en Aquidauana poseen diferentes configuraciones territoriales y geográficas. La TI Limão Verde está ubicada en la zona de transición entre el Cerrado y la llanura del Pantanal en los bordes de la Sierra de Maracaju. Esta ubicación geográfica le brinda un potencial turístico relacionado con el medio ambiente y sus paisajes excepcionales. Las otras TI (Cachoeirinha, Taunay/Ipegue y RI Nossa Senhora de Fátima), están ubicadas en la llanura del Pantanal con atractivos relacionados con la pesca y la naturaleza. En la actualidad, el potencial turístico de la región está relacionado con la exploración turística realizada en las fincas pantaneras. Hay que sumar a ello, la forma de vida, la cultura tradicional manifestada en los hábitos alimenticios, la caza, la pesca, el baile, la artesanía, además de la historia misma de los pueblos, marcada por hechos y épocas que son notables para el país, como la Dictadura Militar. Estas son experiencias únicas que un turista puede recibir al conocer este importante territorio de interés turístico.

El potencial turístico relacionado con el turismo en los territorios indígenas es conocido en la región, un hecho es que en la RS evidencian este potencial, no es cuestionado, tal como lo reconoce la sociedad. Históricamente, el turismo en este territorio se concentra en las fincas del Pantanal y existe la necesidad de expandirlo a otras áreas, que permitan extender la generación de trabajo, empleo e ingresos, siendo el turismo en TI una posibilidad excepcional para las comunidades de la región.

Las RS identificadas en esta investigación, demuestran una variedad de dimensiones, pero en los discursos se evidencian los conflictos presentes en el territorio (áreas ocupadas y retomadas) y las territorialidades, a la vez que evidencian los manejos en el campo posibilitados por el racismo, la discriminación y la exclusión social a que están sometidas las comunidades indígenas. Estas ideas se denotan en los IC de los actores sociales entrevistados, cuando muestran "negativismo, cuestionamiento de la capacidad, asistencia, corrupción, canjes de votos, consumo de alcohol, pereza, falta de cooperativismo, problemas sociales, materialismo", entre otras RS lúdicas.

Por el contrario, los Terena buscan empoderamiento con acciones diversificadas para plantear nuevas posiciones en el campo, en la lucha por sus derechos y sus territorios, pues a lo largo del proceso histórico temporal, desde la llegada de los colonizadores al territorio brasileño, han vivido una secuencia de hechos y acciones perjudiciales y dañinas a sus comunidades. Se puede afirmar, que el imaginario sobre el pueblo Terena estuvo conformado 
por los conflictos que existían en el territorio de Aquidauana, los cuales se manifiestan en el racismo, colonialismo, paternalismo, eurocentrismo y capitalismo.

Los Terena son un pueblo que ha pasado por varios procesos de interacción social, fueron impactados por las formas de vida no indígena, que tuvieron una gran importancia histórica para la región, el estado y el país. No obstante, estas particularidades no impiden que los Terena sean objeto de RS racistas y deslegitimantes.

Al respecto, ciertas narrativas ganaron evidencias en los últimos años, a través del trabajo de actores sociales y agentes dotados de poder político y económico, que apuntan a los territorios indígenas para la exploración de la naturaleza y la producción de commodities (en la región estudiada, estas acciones se evidencian en la agricultura y ganadería extensiva). La productividad de las tecnologías de la información y, junto con ello, las cuestiones laborales, forman parte del discurso eurocéntrico, y se basan en la teleología del progreso que es accionado por diferentes actores sociales, incluido el Estado.

En este sentido, cabe señalar que el turismo comunitario aparece precisamente como un contrapunto a los modelos hegemónicos de "desarrollo" y, en consecuencia, al modelo hegemónico de turismo, que privilegia a algunos agentes. Por tanto, creer que los Terena no trabajarían en el desarrollo del turismo - y más, con el turismo comunitario - solo porque no les importan las prácticas de producción extensiva y guiados por la exploración de la naturaleza, parece ser un discurso carente de comprensión de las formas de vida y cosmología de esa gente.

El turismo comunitario se apoya, como ya se mencionó, en la autonomía y autogestión de actividades, atendiendo a la visión política y social de los pueblos indígenas, que demandan - y tienen garantizado por ley - el derecho a la autodeterminación, a "otro desarrollo". Al mismo tiempo, la diversificación del turismo en la región traería una mayor difusión de los beneficios económicos y sociales, ya que la práctica turística en las fincas del Pantanal ignora a la población local, indígena o no, y limita la cadena de producción turística.

En resumen, la identificación de RS puede contribuir para que agentes públicos y privados, entidades educativas, investigadores, gestores políticos y otros actores sociales, puedan reorientar sus acciones para posibilitar el desarrollo del potencial turístico en las $\mathrm{TI}$ en la región del Pantanal. Las RS presentadas muestran que el racismo y los estereotipos marginales sobre los pueblos indígenas y, específicamente, sobre los Terena, llevan a la población a la incredulidad en la capacidad de estas personas para gestionar proyectos turísticos en sus TI. Esto también demuestra que, aunque las TI y las comunidades indígenas son vistas en todo el mundo como atracciones turísticas, a su vez, estas poblaciones y sus territorios son excluidos del ámbito turístico.

El turismo en las TI debe contar con la participación de organizaciones que no pertenezcan al sector turístico, como FUNAl y organizaciones socio ambientalistas no gubernamentales; lo que sucede en Aquidauana es que los posibles proyectos turísticos formulados por los indígenas, en un principio, requieren contar con el apoyo de actores sociales fuera del municipio, del apoyo del estado e incluso del país.

La presente investigación permite una reflexión sobre la complejidad del turismo en TI brasileñas, demuestra que, aunque esas tierras estén dotadas de atractivos y recursos 
naturales y culturales, este tema no puede abordarse de una manera generalista y menos positivista. Hay que tomar en cuenta una serie de aspectos existentes, entre ellos, los conflictos socio-ambientales, la tenencia de la tierra, el poder político y económico de los indígenas y de otros actores sociales y en el ámbito del turismo, el grado de inclusión de estas poblaciones en el contexto local.

Por otro parte, se debe tomar en cuenta, que el turismo indígena es parte de un movimiento social por el reconocimiento de las diferencias, el control de la tierra, el territorio y el paisaje, como lo expone Pereiro (2016). Además, el turismo comunitario se basa en epistemologías emancipatorias y contra lo hegemónico. Así, esta actividad podría contribuir, por un lado, a fortalecer la territorialidad de los Terena ante el intento de agotar sus tierras y, por otro, a fortalecer la imagen positiva de este pueblo en el contexto regional.

Finalmente, cabe destacar que la segunda fase de esta investigación, que se llevará a cabo durante los próximos años, consistirá en conocer a las Representaciones Sociales de los pueblos indígenas sobre el desarrollo de las TI en el Estado de Mato Grosso do Sul. Se justifica, considerando que el turismo puede ser una alternativa de desarrollo para las comunidades indígenas del estado.

\section{REFERENCIAS BIBLIOGRÁFICAS}

Acçolini, G. (2007). Uniedas: o cotidiano de uma igreja protestante entre os índios Terena. Revista Eletrônica História em Reflexão, 1(2), 1-14, Recuperado de https://tinyurl.com/ybmccx52.

Adam, P. y Herzlich, C. (1994). Sociologie da la Maladie et de Médecine. Paris (FRA): Natham Université.

Alexandre, M. (2004). Representação Social: uma genealogia do conceito. Comum, 10(23),122-138.

Araújo, G. P. y Gelbcke, D. L. (2008). Turismo Comunitário: Uma perspectiva ética e educativa de desenvolvimento. Revista Turismo Visão e Ação, 10(3), 357-378, DOI: 10.14210/rtva.v10n3.p358-377.

Baltazar. P. (2010). O processo decisório dos Terena. Dissertação de Mestrado, Pontifícia Universidade Católica de São Paulo (PUC-SP), São Paulo (BRA).

Bessa Freire, J. R. (2016). Museus Indígenas, Museus Etnográficos e a Representação dos Índios no Imaginário Nacional: o que o museu tem a ver com educação? En M. X. Cury (Org.). Museus e Indígenas: saberes e ética, novos paradigmas em debate (pp. 33-38). São Paulo (BRA): Secretaria da Cultura; ACAM Portinari; Museu de Arqueologia e Etnologia da Universidade de São Paulo.

Bittencourt, C. M. y Ladeira, M. E. (2000). A história do povo Terena. Brasília (BRA): MEC.

Bourdieu, P. (2002). Entrevista por Maria André de Loyola. Rio de Janeiro (BRA), EDUERJ.

Bourdieu, P. (1983). Questões de sociologia. Rio de Janeiro (BRA), Marco Zero. 
Cañada. E. (2010). Perspectivas del turismo comunitario: como mantener vivas las comunidades rurales. Revista Pueblos, 41. Recuperado de https://tinyurl.com/y9lyrrteh.

Cardoso, M. H. C. A. y Gomes, R. (2000). Representações Sociais e História: Referenciais Teórico-Metodológicos para o campo da saúde coletiva. Cadernos de Saúde Pública, 16(2), 499-506. DOI: 10.1590/S0102-311X2000000200020.

Cardoso. W. D. (2004). Aldeia Indígena de Limão Verde: escola, comunidade e desenvolvimento local. Dissertação de Mestrado, Universidade Católica Dom Bosco, Campo Grande (BRA).

Castro, E. V. (2006). No Brasil, todo mundo é índio, exceto quem não é. En B. Ricardo y F. Ricardo (Org.). Povos indígenas no Brasil: 2001-2005 (pp. 41-49). São Paulo (BRA): Instituto Socioambiental.

Chartier, R. (1990). A História Cultural. Entre Práticas e Representações. Lisboa (POR): Difel.

Cepial. (2015). Os Povos Indígenas na América Latina: avanços na última década e os desafios pendentes para a garantia de seus direitos. Comissão Econômica para a América Latina e o Caribe. Santiago (CHL): Cepial.

Conselho do Povo Terena. (2011). Assembléia do Povo Terena de Taunay-Ipegue. Aquidauana (BRA): CIMI. Recuperado de https://tinyurl.com/yc6vrfmf.

Conselho do Povo Terena. (2017). Documento final da 10 Grande Assembleia do Povo Terena. Dois Irmãos do Buriti (BRA): Conselho Terena. Recuperado de https://tinyurl.com/yclyu6dd.

Conselho do Povo Terena (2019). Carta de Ipegue: documento final da 13으ssembleia Terena. Aquidauana (BRA): Conselho do Povo Terena/Apib. Recuperado de https://tinyurl.com/y8yqf3oj.

Corbari, S. D., Bahl, M. y Souza, S. R. (2017). Legislação Indigenista e Perspectivas para o Turismo em Terras Indígenas no Brasil. Revista Turismo em Análise, 28(1), 53-70. DOI: 10.11606/issn.1984-4867.v28i1p53-70.

Costa, S. P. y Sanaglio, K. E. (2014). Análise das Representações Sociais dos comerciantes ambulantes e suas implicações no planejamento turístico. PASOS. Revista de Turismo y Patrimonio Cultural, 12(1), 123-136. DOI: 10.25145/j.pasos.2014.12.009.

Decreto n. 1.775, de 8 de janeiro de 1996 (1996). Dispõe sobre o procedimento administrativo de demarcação das terras indígenas e dá outras providências. Diário Oficial da União, Brasília (BRA).

Decreto n.5.051, de 19 de abril de 2004. (2004). Promulga a Convenção no 169 da Organização Internacional do Trabalho - OIT sobre Povos Indígenas e Tribais. Diário Oficial da União, Brasília (BRA).

Fernandes, V. B. y Souza, M. C. C. C. (2016). Identidade Negra entre exclusão e liberdade. Revista do Instituto de Estudos Brasileiros, 63, 103-120. DOI: https://doi.org/10.11606/issn.2316-901X.v0i63p103-120 
Ferreira, C. (1995). Estilos de vida, práticas e representações sociais dos termalistas. O caso das termas da Curia. Revista Crítica de Ciências Sociais, 43, 93-122. Recuperado de http://hdl.handle.net/10316/10893.

Ferreira, A. C. (2009). Políticas para Fronteira, História e Identidade: a luta simbólica nos processos de demarcação de terras indígenas Terena. Mana, 15(2), 377-410. DOI: 10.1590/S0104-93132009000200003.

Funai. Fundação Nacional do Índio. MS - Violência econômica e territorial contra o Povo Terena. Mapa de conflitos envolvendo injustiça ambiental e saúde no Brasil. Fundação Oswaldo Cruz. Recuperado de https://tinyurl.com/y7s5khxj.

Good, B. y Good, M. D. (1993) Learning medicine: The constructing of medical knowlegde at Havard Medical School. En S. Lindenbaum y M. Locke (Ed.). Knowlegde, Power and Practice (pp. 81-107). Los Angeles (USA): University of California Press.

Grunewald, R. A. (2015). Turismo na Terra Indígena Pataxó de Coroa Vermelha: imperialismo e pós-colonialidade na região do Descobrimento do Brasil. PASOS. Revista de Turismo y Patrimonio Cultural, 13(2), 411-424. Recuperado de https://tinyurl.com/yb5wxmyp.

Guareschi, P.y Jovchelovitch, S. (1994). Textos em Representações Sociais. (4 ed.). Petrópolis (BRA): Editora Vozes.

Guimarães, L. A. M. y Grubits, S. (2007). Alcoolismo e violência em etnias indígenas: uma visão crítica da situação brasileira. Psicologia \& Sociedade, 19(1), 45-51.

Gudynas, E. (2011a). Los derechos de la Naturaleza en sério: respuetas y aportes desde la ecología política. En A. Acosta y E. Martínez (Coord.). La Naturaleza com derechos: de la filosofia a la política (pp. 239-258). Quito (ECU): AbyaYala/Universidad Politécnica Salesiana.

Gudynas, E. (2011b). Debates sobre el desarrollo y sus alternativas en latinoamerica: una breve guía heterodoxa. En M. Lang y D. Mokrani (Org.). Más Allá del Dessarollo - Grupo Permanente de Trabajo sobre Alternativas al Desarrollo (pp. 21-54). Cidade do México (MEX): Fundação Rosa Luxemburg/Abya Yala.

Herzlich, C. (1992). Santé et Maladie: Analyse d'une Représation Sociale. Paris (FRA): Éditons de L'ehess.

IBGE (2010). Indígenas - Censo 2010. Instituto Brasileiro de Geografia e Estatística. Recuperado de https://indigenas.ibge.gov.br/.

ISA (2019). Fazer amigos, proteger territórios: conheça cinco iniciativas de turismo em Terras Indígenas. Instituto Socioambiental. Recuperado de https://www.socioambiental.org/ptbr/noticias-socioambientais/fazer-amigos-proteger-territorios-conheca-5-iniciativas-deturismo-em-terras-indigenas

ISA (2020). Terras Indígenas no Brasil. Instituto Socioambiental. Recuperado de https://terrasindigenas.org.br. 
Instrução Normativa 003, de 11 de junho de 2015 (2015). Estabelece normas e diretrizes relativas às atividades de visitação para fins turísticos em terras indígenas. Brasília: Funai. https://www.gov.br/funai/ptbr/arquivos/conteudo/ascom/2015/doc/jun-06/in-03-2015.pdf

Langdon, E. J. (2001). O que beber, como beber e quando beber: o contexto sociocultural no alcoolismo entre as populações indígenas. En D. A. Noleto (Ed.). Seminário sobre alcoolismo e vulnerabilidade às DST/AIDS entre os povos indígenas da Macrorregião Sul, Sudeste e Mato Grosso do Sul, Brasília, 2000 (pp. 83-97). Brasília: Ministério da Saúde. Recuperado de http://bvsms.saude.gov.br/bvs/publicacoes/021anais seminario.pdf\#page=83.

Lefèvre, F. y Lefèvre, A. M. C. (2003). Pesquisa de Representação Social. Brasília (BRA): Liberlivro.

Lefèvre, F., Lefèvre, A. M. C., y Marques, M. C. C. (2009). Discurso do Sujeito Coletivo, complexidade e auto-organização. Cien Saude Colet, 14(4), 1193-1204. DOI: 10.1590/S1413-81232009000400025.

Lei n. 601, de 18 de setembro de 1850. (1850). Dispõe sobre as terras devolutas do Império. Coleção de Leis do Império do Brasil (CLBR).

Lima, M. E. O. y Almeida, A. M. M. (2010). Representações sociais construídas sobre os índios em Sergipe: ausência e invisibilização. Paideia, 20(45), 17-27. Recuperado de https://www.scielo.br/pdf/paideia/v20n45/a04v20n45.pdf.

Maldonado, C. (2006). Turismo y comunidades indígenas: impactos pautas para autoevaluación y códigos de conducta. Genebra (SUI): SEED.

Milanez, F., Sá, L., Krenak, A., Cruz, F., Urbano, E., y Pataxó, G. S. (2019). Existência e diferença: o racismo contra os povos indígenas. Revista Direito Práxis, 10(3), 2161-2181. DOI: 10.1590/2179-8966/2019/43886.

Morera, J. A., Padilha, M. I., Silva, D. G., y Sapag, J. (2015). Aspectos Teóricos e Metodológicos das Representações Sociais. Texto Contexto Enfermagem, 24(4), 1157-1165. DOI: 10.1590/0104-0707201500003440014.

Morris, D. B. (1998). Illness and Culture in the Postmodern Age. Berkeley/Los Angeles (USA)/London (ENG): University of California Press.

Moscovici, S. (1976). A Representação social da psicanálise. Rio de Janeiro (BRA), Zahar.

Moscovici, S. (1961). La Psychanalyse son image et son public (2 ed.) Paris (FRA): PUF.

Moscovici, S. (2003). O Fenômeno das Representações Sociais. En S. Moscovici (Ed.), Representações Sociais: investigações em psicologia social (pp. 29-109). Petrópolis (BRA): Vozes.

Moscovici, S. (2012). A psicanálise, sua imagem e seu público. Petrópolis (BRA): Editora Vozes. 
Neves, S. C. (2015). A Domesticação do Turismo: estratégias Pataxó na relação com agentes e agências de turismo em Coroa Vermelha. PASOS. Revista de Turismo y Patrimonio Cultural, 13(3), 567-580. Recuperado de http://www.pasosonline.org/Publicados/13315/PASOS42.pdf\#page=129.

OBSTUR (2020). Fluxo de Passageiros. Observatório de Turismo de Mato Grosso do Sul. Recuperado de encurtador.com.br/eipq2.

Oliveira, J. E. (2016). Conflitos pela posse de terras indígenas em Mato Grosso do Sul. Ciência e Cultura, 68(4), 4-5. DOI: 10.21800/2317-66602016000400002.

Paiol. (s. d.). Etnias. Recuperado de https://lojapaiol.com.br/etnias/.

Pereiro, X. (2013). Los efectos del turismo en las culturas indígenas de América Latina, Revista Española de Antropología Americana, 43(1), 155-174. DOI: 10.5209/rev_REAA.2013.v43.nl.42308.

Pereiro, X. (2016). A review of Indigenous tourism in Latin America: reflections on an anthropological study of Guna tourism (Panama). Journal of Sustainable Tourism, 24(89), 1121-1138. DOI:10.1080/09669582.2016.1189924.

Portaria n. 389, de 9 de mio de 2013. (2013). Cria o Programa de Bolsa Permanência e dá outras providências. Diário Oficial da União, Brasília (BRA). Recuperado de https://tinyurl.com/ybpsbhlf.

Reis, S. L. A.y Bellini, M. (2001). Representações Sociais: Teoria, Procedimentos Metodológicos e Educação Ambiental. Revista Educação Ambiental e Ação, 37(10). Recuperado de http://www.revistaea.org/artigo.php?idartigo=1081.

Reigota, M. (2002). Meio Ambiente e Representação Social (5. ed.) São Paulo: Cortez.

Robbins, P. (2012). Political ecology: a critical introduction. Malden (USA): Wiley-Blackwell.

Rocha Filho, J. F. (2010). No ritmo das águas, na cadência da boiadas. A inserção do turismo nas fazendas de criação extensiva de gado bovino no Pantanal de Aquidauana/MS. Dissertação de Mestrado, Universidade de São Paulo, São Paulo (BRA).

Sampaio, C. C. (2005). Turismo como fenômeno humano: princípios para se pensar a socioeconomia e sua prática sob a denominação turismo comunitário. Santa Cruz do Sul (BRA): EDUNISC.

Souza, E. P., Martins, S. R. O., y Araújo, A. P. C. (2011). Fronteira Etnocultural e Desenvolvimento Rural: o produto turístico "trem do pantanal" no Distrito de Taunay. Acta Geográfica, 5(10), 37-53. DOI: 10.5654/actageo2011.0510.0003.

Trevisol, J. V. (2004). Os Professores e a Educação Ambiental: um estudo de representações sociais em docentes das Séries Iniciais do Ensino Fundamental. Papers II Encontro do Encontro da Associação Nacional de Pós-graduação e Pesquisa em Ambiente e Sociedade (Anppas). São Paulo (BRA).

Trevisol, J. V. y Socolovski, M. (2000). Meio Ambiente e Educação Ambiental: um estudo de representações sociais em professores da rede municipal de ensino de Campos Novos - SC. Revista Roteiro, Joaçaba (BRA), 24 (44), 27-56. 
UFMS. (2018). El Proyecto Turismo en Tierras Indígenas se llevó a cabo con éxito en CPAQ. Universidade Federal do Mato Grosso do Sul. Recuperado de https://www.ufms.br/projeto-turismo-em-terras-indigenas-foi-realizado-comsucesso-no-cpaq/:

Palomino-Villavicenzio, B., Gasca Zamora, J. y López Pardo, G. (2016). El turismo comunitario en la Sierra Norte de Oaxaca: perspectivas desde las instituciones y la gobernanza en territorios indígenas. El Periplo Sustentable, 30, 6-37. Recuperado de https://tinyurl.com/yby87cl4.

Williams, R. (1990) A Protestant Legacy: Attitudes to Death and Illness Among Older Aberdonians. Oxford (ENG): Clarendon Press.

Ximenes, I. G., y Pereira, L. M. (2017). O território terena: da expropriação e formação das reservas ao movimento das Retomadas. Mediações - Revista de Ciências Sociais, 22(2), 24-50. Recuperado https://tinyurl.com/yaobvlxv.

\section{CONTRIBUCIONES DE LOS AUTORES:}

Autor 1: el diseño original de la obra, el análisis, adquisición e interpretación de los datos, la redacción y revisión crítica del contenido, la aprobación final de la versión a publicar.

Autor 2: el diseño original de la obra, el análisis, adquisición e interpretación de los datos, la redacción y revisión crítica del contenido, la aprobación final de la versión a publicar.

Autor 3: análisis, adquisición e interpretación de datos, redacción y revisión crítica de contenidos, aprobación final de la versión a publicar.

Autor 4: análisis, adquisición e interpretación de datos, redacción y revisión crítica de contenidos, aprobación final de la versión a publicar. 